\title{
Synthesis of Piperitone Epoxide and P-Menthane-8-Thiol-3-One from Essential Oils
}

\author{
Abubakar Sani \\ Department of Pure and Industrial Chemistry \\ Umaru Musa Yar'adua University \\ Katsina, Nigeria
}

\begin{abstract}
Buchu (Barosma betulina) is a small flowering plant found in the family Rutaceae in Western Cape of South Africa, Namibia and Australia, capable of growing up to 2 meters with a simple rounded leaf that produced essential oil of strong peppermint and sweetish smell. The Buchu oil as an essential oil consist of many chemical constituents, the main components includes piperitone, pulegone, piperitone epoxide, iso-menthone, P-menthane-8-thiol3-one, 4-diosphenol. The piperitone epoxide and $P$ menthane-8-thiol-3-one constituents in Buchu oil have high commercial values, which extensively used as fragrances in perform, flavor, food additives, tonic and medicinal stimulant in modern medicine in the manufacture of insecticides, antimicrobial, antiinflammatory and antioxidant in cosmetic products. The extinction threat of the plant and chemistry benefit of these chemical constituents initiate scientist with synthetic route for synthesizing the compounds from Eucalyptus dives oil and pennyroyal oil, which are also an essential oils and abundant in nature. In the synthesis, purified piperitone and pulegone from the Eucalyptus dives oil and pennyroyal oil produced two enatiotiomers of piperitone epoxide and P-menthane-8thiol-3-one respectively. The analytical analysis such infrared and GC-Mc conducted for the starting materials, synthesis processes and synthesize products showed results of significant value in terms chemical reactions and structural re-arrangement.
\end{abstract}

Keywords:- Buchu (Barosma betulina), Eucalyptus dives oil, pennyroyal oil, piperitone, pulegone, piperitone epoxide, p-menthane-8-thiol-3one, TGA, Infrared spectroscopy, GC-MS.

\section{INTRODUCTION}

The term essential oils derived its name as an extract from the characteristics fragrance of the plant from which is obtained. They are complex aromatic, volatile compositions oils of obtained from a plant source or material either by steam or dry distillation, using a suitable heating or mechanical method of extraction and usually carry the odour of their plant [1]. In addition, essential oils being aromatic in nature are basically extracted from aromatic plant sources, mostly biosynthesis by the plant organs as secondary intermediate products. The aromatic plants make only $10 \%$ of over 1700 plant species globally and the genres can be traced in a small number of families, which includes Asteraceae, Rutaceae, Piperaceae Lauraceae, Lamiaceae,

\author{
Muhammad Sulaiman Rahama \\ Department of Pure and Industrial Chemistry \\ Umaru Musa Yar'adua University \\ Katsina, Nigeria
}

Myrtaceae, cupressaceae, and Poaceae. The essential oils as a volatile complex mixture of compounds obtained from aromatic plant extracts can be categorised into two distinct groups based on the chemical composition. These includes hydrocarbons compounds which are made up of terpenes (isoprenes), terpernoids that is subdivided into monoterpenes, sesquiterpenes, diterpenes and the oxygenated compounds which consist of mainly aldehydes, ketones, alcohols, phenol and oxides [1,2]. The isoprene unit is also the basic building block of terpenes with general formula of $\left(\mathrm{C}_{5} \mathrm{H}_{8}\right)_{n}$, where ' $\mathrm{n}$ ' represents the number of attached isoprene units. The linkage system of isoprene units is in head-to-tail arrangement [2].

The essential oils been products of secondary metabolites of aromatic plants are composed of complex mixture of volatile constituents that are used in flavourings, perfumes, insects and animal repellents. They are also used in cosmetics and aromatherapy applications as an antiinflammatory, anti-septic, anti-viral and anti-bacterial [3]. The essential oils can be served as food supplements for lactating animals as well as food preservatives [4]. These oils are mainly extracted from different plant sources.

Buchu oil, an essential oil mainly produced from Buchu plant, consist of many compounds. Buchu plant is extensively used as tonic and medicinal stimulant. Among the main chemical constituents found in the Agathosma betulina specie are limonene, cis mercaptone, trans mercaptone, l-pulegone, piperitone, piperitone epoxide, diosphenol, d-pulegone, 4-diosphenol, iso-menthone and menthone. In the specie of Barosma crenulata, significant amount of 1-pulegone, P-menthane-8-thiol-3-one, limonene, cis acetylthiol, trans acetylthiol, cis mercaptone, trans mercaptone, menthone and trace of diosphenol are found. The 1-pulegone is exerting toxicity effect, if consumed in large quantities [5]. The essential oil obtained from Eucalyptus dives tree is usually produced by steam distillation, having two chemotype of piperitone and cineole. The piperitone chemotype of Eucalyptus dives (53\% composition of piperitone) has a peppermint aroma and flavor and can be used in the production and synthesis of menthol, piperitone, thymol etc. while the cineole chemotype of Eucalyptus dives is uncommon in nature and rich in with cineole about $70-80 \%$ composition [6]. The dominant chemical compositions in Eucalyptus dives (E. dives) essential oil are $(40.5 \%)$ piperitone, (17.4\%) phellandrene, $(8.5 \%)$ para-cymene and $(4.7 \%)$ terpin-4-ol [7]. The distillate heavy product of the Eucalyptus dives specie found in South Africa contains significant amount 
piperitone, while the distillate light product contains high quantity of $\alpha$-thujen, $\alpha$-terpinolene and $\alpha$-phellandrene with several other volatiles. The Australian specie of Eucalyptus dive has a unique advantage of high piperitone content extracts $(42.9 \%)$ and $\alpha$-phellandrene $(30.0 \%)$ as the dominant constituents in the essential oil. Current attention and interest have been now focusing on the synthetic chemistry of their functional group properties to synthesize numerous compounds of commercial value such as menthol, piperitone epoxide etc. The E. dives essential oil has different colour ranges from colourless when refined to pale yellow when first obtained by steam fractional distillation of the leaves. The E.dives essential oil possesses wide applications in chemical purposes and pharmaceutical formulation. This includes insect repellent, antiseptic, flavour in in food and fragrance manufacture, and as a starting material or component for industrial compounds. It also showed antimicrobial activity against yeast and other bacterial infection, which can be used in cosmetic formulation.

Pennyroyal popularly known as Mentha pulegium is an aromatic flowering plant that belongs to the family lamiaceae. Its volatile essential oil obtained by steam distillation or hydro-distillation of Mentha pulegium L. (European pennyroyal specie) and Hedoema pulegiodes L. (American pennyroyal specie), basically from the leaves and flowering tops. The crushed leaves of pennyroyal produced a strong aroma of almost similar to spearmint smell and the pungent odour of it essential oil is related to the high composition of pulegone which is toxic organic compound [8]. According to the Petrakis et al [80], the main constituents of pennyroyal essential oil consists of pulegone $(61.3 \%-77.9 \%)$, iso-menthone $(10.6 \%-18.5 \%)$, piperitone $(0.3 \%-3.2 \%)$, menthone $(0.6 \%-8.3 \%)$ and cis-iso pulegone $(0-1.7 \%)$, while another analysis states that, the Mentha pulegium (European origin) essential oil is made up of 53 different constituents, making up of $86.3 \%$ of the oil composition.

This work would focus on the synthesis and characterization of piperitone epoxide and p-menthane-8thiol-3-one, being important constituents of Buchu oil (Barosma betulina spp.) from eucalyptus dives oil and pennyroyal oil. These compounds have economic values in terms of wider application in traditional and modern medicinal science and flavours, fragrances and cosmetics usage. The commercial high demand of these compounds exposes the plant to the extinction threat, which motivates scientist to initiate synthetic routes to manufacture major constituents in the Buchu oil.

\section{METHODOLOGY}

\section{A. Reagents}

The solvents and reagents used in the research work includes sodium hydroxide (Reagent grade, $\geq 98 \%$, pellets (anhydrous) sigma-aldrich), sodium hydrogen sulfite (Purum, 40\% sigma-aldrich), diethylamine ( $\geq 99.5 \%$ sigmaaldrich), sodium sulfate (ACS reagent, $\geq 99 \%$ anhydrous, granular, sigma-aldrich), 30\% hydrogen peroxide (30wt, $\%$ in $\mathrm{H}_{2} \mathrm{O}$ reagent, sigma-aldrich), methanol (CHROMA SOLV® Plus, for HPLC, $\geq 99.9 \%$ sigma-aldrich), acetone (CHROMA SOLV® Plus, for HPLC, $\geq 99.9 \%$ sigmaaldrich), n-hexane (CHROMA SOLV® Plus, for HPLC, $\geq$ $97.0 \%$ (GC) sigma-aldrich), hydrochloric acid (ACS reagent, 37\% sigma-aldrich), diethyl ether (ACS reagent, anhydrous, $\geq 99.7 \%$ sigma-aldrich), iron (ii) sulfide (technical grade, sigma-aldrich), Pennyroyal oil ( $\geq 90 \%$ aldrich) and Eucalyptus dives oil ( $\geq 90 \%$ aldrich). All reagents are purchased and supplied by Sigma Aldrich chemical company Inc.

\section{B. Apparatus}

Three neck $100 \mathrm{ml}$ round bottom flask, two neck 100 $\mathrm{ml}$ round bottom flask, fractionating column, condenser, thermometers, beakers, separating funnel, dropping(addition) funnel, adaptors, funnel, magnetic stirrer, vials, rotatory evaporator etc.

\section{Piperitone Purification from Eucalyptus dives oil}

The purification procedure consisted of reaction stages, whereby $10 \mathrm{ml}$ of Eucalyptus dives oil was treated and well shaken with excessive saturated sodium hydrogen sulfite for an hour, which produced a white precipitate of complex mixture of aldehydes and ketones. The mixture was treated and washed with portions of methanol and diethyl ether for the purification. The solution obtained was dissolved in hot water and a few drops of $1 \mathrm{M}$ of sodium hydroxide were added to regenerate ketone compounds before drying with sodium sulfate. Fractional distillation was setup to isolate piperitone at temperature range between $94-96{ }^{\circ} \mathrm{C}$.

\section{Piperitone Epoxide}

The experiment involved an epoxidation reaction of pure piperitone obtained from experiment $1.5 \mathrm{ml}$ of pure piperitone was treated with $10 \mathrm{ml}$ of $30 \%$ Hydrogen Peroxide $\left(\mathrm{H}_{2} \mathrm{O}_{2}\right)$ in $16 \mathrm{ml}$ methanol at $-15^{\circ} \mathrm{C}$. Furthermore, $3 \mathrm{ml}$ of $6 \mathrm{M}$ aqueous sodium hydroxide was added with stirring ensuring the temperature of the reaction did not exceed $0{ }^{\circ} \mathrm{C}$. After the addition was complete, the mixture was continued stirring for further two hours. $20 \mathrm{ml}$ of cold water was added to the mixture and extracted four times with portion of diethyl ether $(4 \times 12 \mathrm{ml})$. The extract was also washed with water and dried using anhydrous sodium sulfate. A small quantity of diethyl ether remaining in the extract was removed using a rotary evaporator at $32{ }^{\circ} \mathrm{C}$ and the Piperitone epoxide was distilled at $105^{\circ} \mathrm{C}$ by fractional distillation.

\section{E. P-menthane-8-thiol-3-one}

This is an experiment involved the synthesis of organosulfur compound ( $\mathrm{p}$-menthane-8-thiol-3-one) from $\mathrm{d}$ pulegone obtained from fractional distillation of pennyroyal oil. The synthesis processes includes the immersion of $5 \mathrm{ml}$ of d-pulegone into $5 \mathrm{ml}$ diethylamine in a cooling bath. A continued flow of hydrogen sulfite gas was bubbled into the reaction mixture for 5 hours and the temperature of reaction did not exceed $30{ }^{\circ} \mathrm{C}$. A crystalline residue was obtained, which was acidified with hydrochloric acid and extracted two times with portion of ether $(2 \times 10 \mathrm{ml})$. The extract was washed with water and dried with anhydrous sodium sulfate. 
A small quantity of diethyl ether remaining was removed using rotatory evaporator from the extract and a yellow oil of thiol compound is obtained.

\section{F. Instrumental Analysis}

Thermogravimetric analysis (TGA) was carried out on the starting materials (i.e. essential oils) to provide a quantitative measurement of weight loss changes associated with thermally induced transitions. The technique was necessary due to fractional distillation process in the research work that is conducted in isothermal conditions. The TGA operating parameters are as follows:

Mass of sample: $7.0593 \mathrm{mg}$ of pennyroyal oil

Start temperature: Ambient

Heating rate: $10^{\circ} \mathrm{C} \mathrm{min}{ }^{-1}$

Atmosphere: Nitrogen $20 \mathrm{ml} \mathrm{min}^{-1}$

End temperature: $500{ }^{\circ} \mathrm{C}$

Pan: Platinum

For each analysis, $7.0593 \mathrm{mg}$ of the sample was measured in the sample pan and transferred into the instrument for the analysis under the above set of parameters. A thermogram was obtained after the analysis, showing a derivative curve of mass change against temperature change.

Gas chromatograpy-Mass spectrometry (GC-MS) was used to identify the components present in the oil using an Agilent Technologies 6890N GC System with an ID-BPX5 column $(30 \mathrm{~m} \times 0.25 \mathrm{~mm} \times 0.25 \mu \mathrm{m})$. The electron energy and source temperatures were $70 \mathrm{eV}$ and $280{ }^{\circ} \mathrm{C}$ respectively. The GC was operated under an injection split mode.

Attenuated total reflection Fourier trans-infrared (ATR-FTR) spectroscopy was used to analyse the surface attached molecules and determine thieir secondary structural pattern, orientation and interaction. The analysis of these compounds was conducted under following conditions: scanning times of 8 , resolution $4 \mathrm{~cm}^{-1}$ and scanning frequencies ranges from $400-4000 \mathrm{~cm}^{-1}$. The background spectrum was carried out before each of the samples was placed on the attenuated total reflectance cell provided with a diamond crystal. The spectral curves were recorded using OMNIC software programmed in the instrument.

\section{RESULTS}

\section{A. Infrared Analysis}

Fig. 1 shows the spectrum for Eucalyptus dives oil. It revealed two strongly absorbing peaks at about 3000 and $1700 \mathrm{~cm}^{-1}$ for $\mathrm{C}-\mathrm{H}$ and $\mathrm{C}=\mathrm{O}$ stretching frequencies respectively. The intense peak at around $2957.86 \mathrm{~cm}^{-1}$ corresponds to $\mathrm{C}-\mathrm{H}$ stretch (aromatic) and the peak at around $2870.69 \mathrm{~cm}^{-1}$ is assigned to methyl and methylene stretching. The strong absorption at $1668.02 \mathrm{~cm}^{-1}$ corresponds to carbonyl group $(\mathrm{C}=\mathrm{O})$ in piperitone, which is intense due to the strong absorption of infrared radiation by the $\mathrm{C}=\mathrm{O}$ bond. The absorbance at $1637.54 \mathrm{~cm}^{-1}$ is assigned to alkene $(\mathrm{C}=\mathrm{C}$ bond $)$ and also the peak at around 1431.46 and $1366.88 \mathrm{~cm}^{-1}$ corresponds to $\mathrm{C}-\mathrm{H}$ bend and $\mathrm{CH}_{3}$ bend respectively. Aromatic stretch (out-of-plane bend) is observed at $815.66-890.71 \mathrm{~cm}^{-1}$.

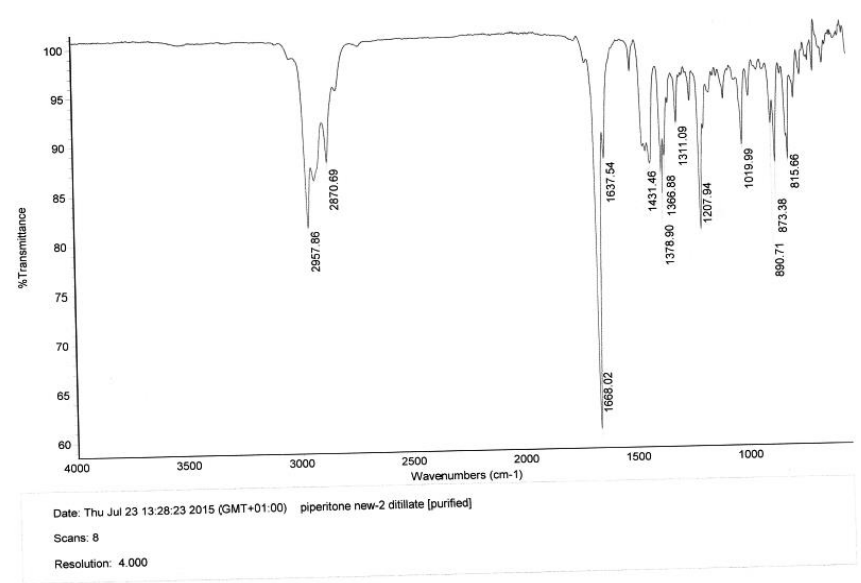

Fig 1:- Infrared spectrum of Eucalyptus dives oil

The pure piperitone spectrum exhibited similar characteristic to the Eucalyptus dives oil IR spectrum in terms of structural information and frequencies at which various functional group absorbed infrared radiation (Fig.2). The significant differences is observed in the intense absorption bands of C-H stretch (aromatic) at $2958.45 \mathrm{~cm}^{-1}$ and slightly shift of carbonyl group $(\mathrm{C}=\mathrm{O})$ from 1668.02 $\mathrm{cm}^{-1}$ in Eucalyptus dives oil to $1671.78 \mathrm{~cm}^{-1}$ for the pure piperitone, which is within the carbonyl group frequencies range $\left(1850-1630 \mathrm{~cm}^{-1}\right)$.

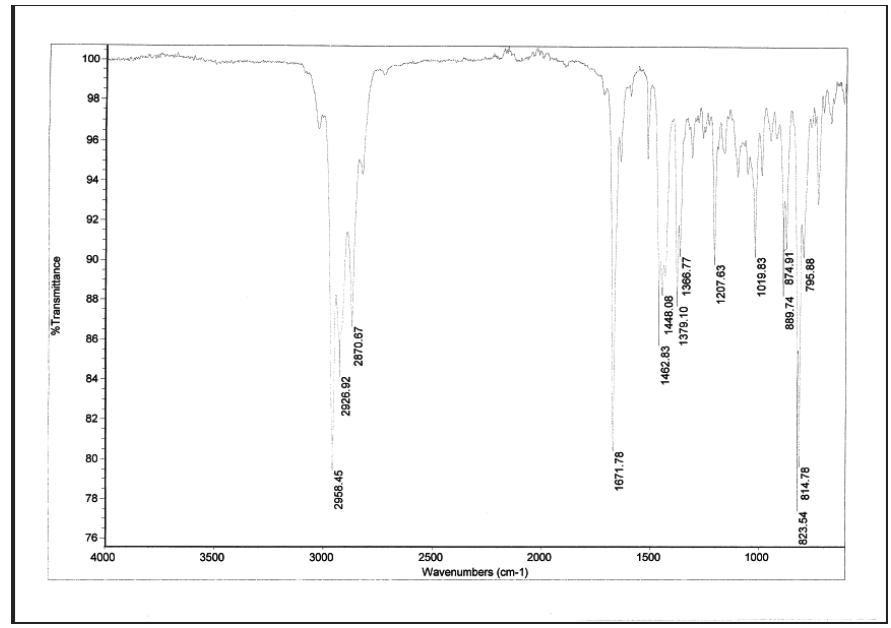

Fig 2:- Infrared spectrum of pure piperitone

Fig. 3 showed the spectrum of piperitone epoxide. The spectrum showed two intense absorbing peaks and numerous peaks in the fingerprint region. The strong absorption peak at $2959.37 \mathrm{~cm}^{-1}$ is assigned to $\mathrm{C}-\mathrm{H}$ stretch (aromatic) and the band at $2930.26 \mathrm{~cm}^{-1}$ corresponds to methyl stretching. The strong peak observed at $1701.75 \mathrm{~cm}^{-1}$ is assigned to unconjugated carbonyl group $(\mathrm{C}=\mathrm{O})$. The distinct weak and strong peaks at 1278.10 and $798.40 \mathrm{~cm}^{-1}$ in the fingerprint region were assigned to ring-stretch and asymmetric ring deformation of the epoxide ring respectively. 


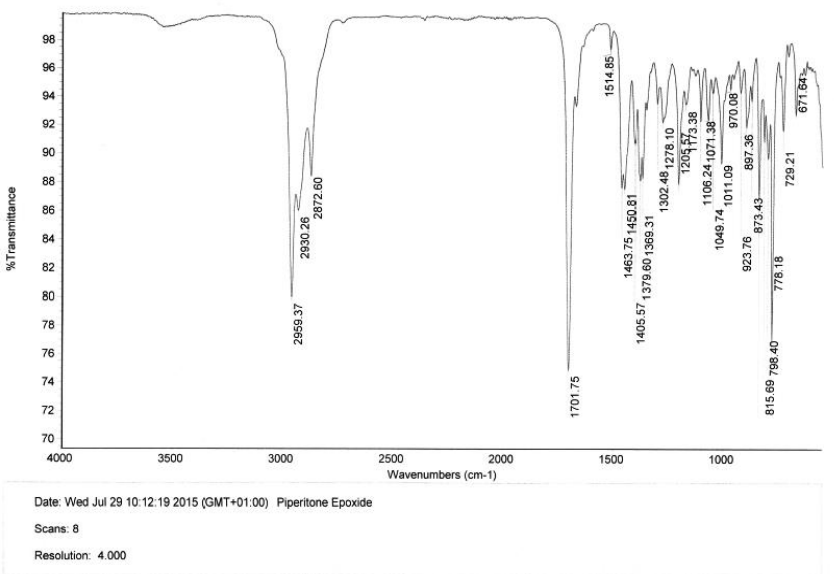

Fig 3:- Infrared spectrum of Piperitone epoxide

As shown in Fig.4, the pulegone spectrum showed two strongly absorbing peaks at about 3000 and $1700 \mathrm{~cm}^{-1}$ for C$\mathrm{H}$ (aromatic) and $\mathrm{C}=\mathrm{O}$ stretching frequencies respectively. The intense peak at around $2953.85 \mathrm{~cm}^{-1}$ corresponds to $\mathrm{C}-\mathrm{H}$ stretch (aromatic) and the peak at around $2870.69 \mathrm{~cm}^{-1}$ is assigned to methyl and methylene stretching. The strong absorption at $1668.02 \mathrm{~cm}^{-1}$ corresponds to the carbonyl group $(\mathrm{C}=\mathrm{O})$ in pulegone, which is intense due to strong absorption of infrared radiation by $\mathrm{C}=\mathrm{O}$ bond. The absorbance at $1618.64 \mathrm{~cm}^{-1}$ is assigned to alkene $(\mathrm{C}=\mathrm{C}$ bond) and also the peak at around 1455.07 and $1363.45 \mathrm{~cm}^{-1}$ corresponds to $\mathrm{C}-\mathrm{H}$ bend and $\mathrm{CH}_{3}$ bend respectively. Aromatic stretch (out-of-plane bend) is observed at 645.51 $875.54 \mathrm{~cm}^{-1}$.

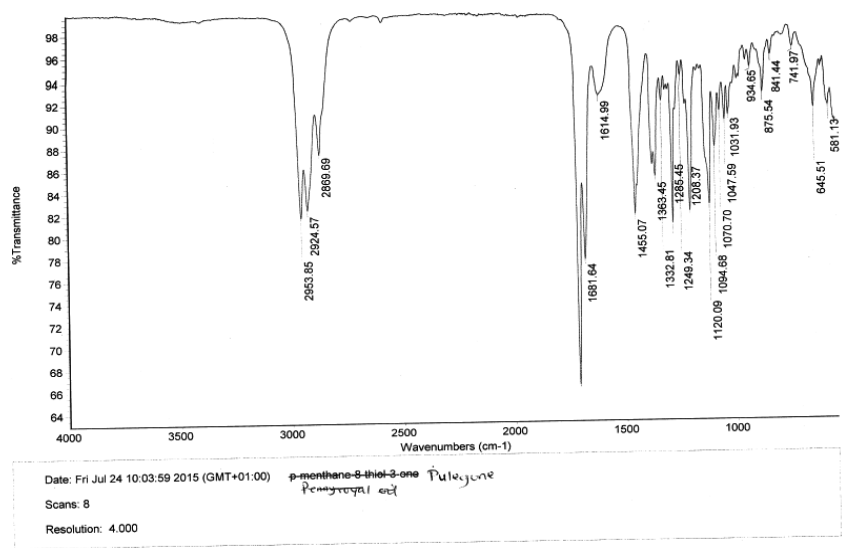

Fig 4:- Infrared spectrum of pulegone

The spectrum showed dominate absorption peaks characteristics of $\mathrm{C}-\mathrm{H}$ stretch at $2953.59 \mathrm{~cm}^{-1}$ and $\mathrm{C}=\mathrm{O}$ stretch at $1708.60 \mathrm{~cm}^{-1}$. The weak absorption band of S-H stretch at $2361.90 \mathrm{~cm}^{-1}$ is observed, which corresponds to the thiol group. The absorbance at $1618.57 \mathrm{~cm}^{-1}$ is assigned to the alkene $(\mathrm{C}=\mathrm{C}$ bond $)$ and also peak at around 1455.20 and $1366.65 \mathrm{~cm}^{-1}$ corresponds to $\mathrm{C}-\mathrm{H}$ bend and $\mathrm{CH}_{3}$ bend respectively. Aromatic stretch (out-of-plane bend) is observed at $645.57-875.87 \mathrm{~cm}^{-1}$.

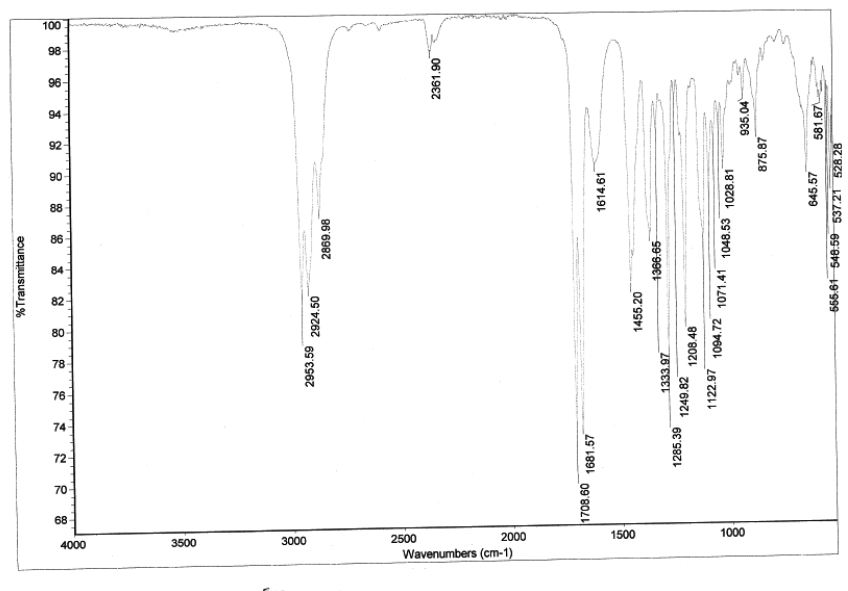

Fig 5:- Infrared spectrum of P-menthane-8-thiol-3-one

\section{B. TGA Analysis}

Fig. 6 reveals the TGA analysis of pennyroyal oil. The pennyroyal oil was heated from $35.55{ }^{\circ} \mathrm{C}$ to $500{ }^{\circ} \mathrm{C}$ (at heating rate $10{ }^{\circ} \mathrm{C} \mathrm{min}^{-1}$ ) in a dry nitrogen atmosphere, flowing at $20 \mathrm{ml} \mathrm{min}{ }^{-1}$. The curve obtained in nitrogen atmosphere has shown starting decomposition at temperature of $140.40^{\circ} \mathrm{C}$ and the weight loss process ended at $215.18{ }^{\circ} \mathrm{C}$. The TGA curve showed the endothermic curve of the analysis, which reflects the characteristic by pointing from maximum value to the baseline as weight loss with temperature increases, which exhibits zero order kinetics. The inflection point of pennyroyal oil obtained from the TGA curve of $157.05^{\circ} \mathrm{C}$ is slightly low compare to other essential oils such as long pepper of inflection point of $182.05^{\circ} \mathrm{C}{ }^{[31]}$, similar to cinnamaldehyde $\left(163{ }^{\circ} \mathrm{C}\right)$, Eugenol $\left(162{ }^{\circ} \mathrm{C}\right)$ higher than cineole $\left(101{ }^{\circ} \mathrm{C}\right)$ and almost the same with cinnamon oil $\left(156^{\circ} \mathrm{C}\right)$ [10].

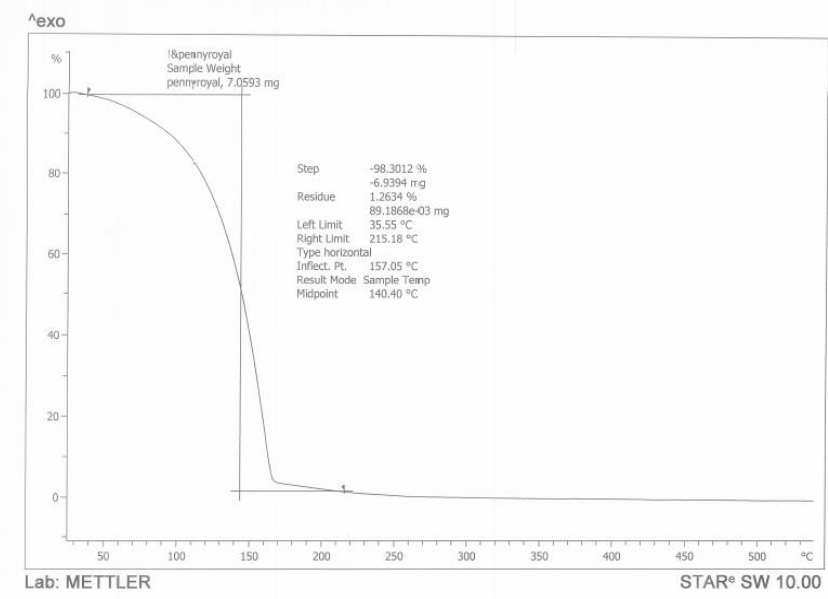

Fig 6:- TGA curve of Pennyroyal oil sample

\section{Reaction Mechanism for Piperitone purification}

The piperitone purification involved the nucleophilic addition of bisulfite to form a chemical bond [11]. The plane polarized nature of $\mathrm{C}=\mathrm{O}$ group makes the carbon atom partial charge and attracts negatively charged nucleophile. 
In the double bond of carbon-oxygen atoms, the electrons are not shared equally. The carbon atom has partial positive charge and the pi electron of the carbonyl bond moves toward to the oxygen atom which is more electronegative than the carbon; therefore, the carbon atom has a strong tendency to attract electrons to itself in a carbon-oxygen bond. This causes the carbon-oxygen double bond to be highly polar in a nature [12].

The bisulfite ion from the sodium hydrogen sulfite produced a weak acid and covalent molecule that dissociates and loses a hydrogen ion, leaving an electron behind on the sulfite ion, with negative charge.

The carbonyl double bond is made up of $\sigma$ and $\pi$ bond. The $\sigma$ bonds between carbon and oxygen hybridized atoms produced two $\mathrm{sp}^{2}$ orbitals. The $\mathrm{sp}^{2}$ orbitals on the carbon atom form two $\sigma$ bonds to the substituents and the other $\mathrm{sp}^{2}$ orbitals of the oxygen are filled by two lone pairs. This makes the carbonyl group to be plane polarized in nature [12].

The Nucleophilic addition reaction occurred between the sulfite ions with the positive carbon atom to formed single bond, while the negative ion of the oxygen atom removed a hydrogen ion from the bisulfite molecule to form another single bond respectively. The sodium hydroxide added in the reaction regenerate piperitone in its pure form by reversing the mechanism. About $7 \mathrm{ml}$ of pure piperitone was obtained after the fractional distillation.

\section{Reaction Mechanism for Piperitone epoxide}

This reaction involves methanol deprotonation of hydrogen peroxide (good oxidizing agent), which provides an active site for $\mathrm{Na}+$ attached to the peroxide forming a conjugate base of hydrogen peroxide (acid-base reaction). The $\mathrm{Na}+$ arises from the dissociation of sodium hydroxide in the reaction. Methanol acts as a nucleophile in the reaction, thereby establishing a nucleophilic attack on the electron-deficient double bonds of piperitone by donating a pair of protons, forming a $\mathrm{C}-\mathrm{H}$ bond (exothermic reaction). This protonation converts the carbon atom into carbonium ion (reactive carbon) which becomes susceptible to nucleophile attack of conjugated base of peroxide. A recycled methanol molecule is obtained after this reaction.

Asymmetric carbon atom is formed from the nucleophilic attack on the double bonds, which features the causes of chirality in the new compound to be formed (Piperitone epoxide). An asymmetric carbon atom is carbon atom attached to four different group atoms or atoms [13].

A weak single bond in the conjugated base of hydrogen peroxide (a better nucleophile) dissociate into $\mathrm{Na}+$ and ${ }^{-} \mathrm{OOH}$ radicals, attacked the carbocation of piperitone compound either from above or below of the bond. This sets up migration reactions, in which the asymmetric carbon atom released a hydrogen ion and reacts with hydroxide ion of peroxide, while hydroxide ion and sodium ion formed sodium hydroxide.
Two optical isomers of "R" and " $S$ " piperitone epoxide are expected at the end of the reaction (enantiomers) due to asymmetrical double bonds reaction.

\section{E. Reaction Mechanism for P-menthane-8-thiol-3-one}

Diethylamine is a good nucleophile for conjugation addition reactions, possessing nitrogen atom with an unshared electron pair that act as nucleophiles toward the alkene (double bonds) of the d-pulegone. This type of nucleophilic addition reaction occurs when the carboncarbon bond has a carbonyl group adjacent to it [13]. The dpulegone is a compound with double bonds adjacent to carbonyl group, also known as $\alpha, \beta$ unsaturated carbonyl compound. The $\alpha$ and $\beta$ signs indicate the distance of the double bonds from the carbonyl group, where the $\alpha$ carbon is the carbon atom next to carbonyl group while the $\beta$ carbon is the one further down the chain of the structure.

The nitrogen of the diethylamine protonates and became positively charged by interacting with hydrogen sulfite gas. The hydrogen sulfite ion produced, attacked the double bonds of d-pulegone by donating an electron to form single bond. An acidified hydrochloric acid is added, prevents the further protonation of diethylamine.

The alkene bond being a planar (flat) exposed the carbon atom to a nucleophilic attacked either from above or below the plane of d-pulegone compound [14].

\section{CONCLUSION}

In this research work, a variety of analytical experiments and instruments were applied to purify, separate and identify the actual constituents using techniques such as TGA, GC-MS analysis and ATR-FTIR analysis. The results provided by the experiment methodologies and instrumental analysis yielded results that satisfied the setting objectives of the research work. In the TGA analysis, the result obtained showed the inflection point of pennyroyal oil $\left(157{ }^{\circ} \mathrm{C}\right)$ falls within the range of inflection point of most the essential oils such Eugenol (162 $\left.{ }^{\circ} \mathrm{C}\right)$, cinnamon $\left(156{ }^{\circ} \mathrm{C}\right)$ etc. In the infrared analysis slight shift of structural bonds was observed, which indicates chemical reactions and synthesis re-arrangement of reacting species is occurring. The stereoisomers expected in the synthesis pathways of the research, appeared in GC-MS chromatograph, but also new synthesize compounds were also observed in the results. Further experiments and analytical processes are required to purify, separate and select the starting compounds and synthesize products such as column chromatography etc. The chiral compounds formed in the research, which exhibits racemic mixture characteristics. The chirality of the products can be overcome by using chiral GC, chiral electrophoresis, chiral capillary electrophoresis and chiral separation capillary electrophoresis. The racemic mixture can also be prevented with the use of chiral chromatograph and enantioselective reactions using chiral reagents or chiral catalyst. Azeotropic mixture of compounds should be considered during distillation process in the research. 


\section{REFERENCES}

[1]. E.A. Asbahani, A.K. Miladi, and A. Elaissari, "Essential oil from extraction to encapsulation," J. Pharm, vol. 483, pp. 220-243, 2015.

[2]. P. Tongnuanchan, and S. Benjakul, "Essential Oils: Extraction, Bioactivities, and Their Uses for Food," J. Food. Sci, vol 79, pp. R1231-R1249, 2014.

[3]. A.M. Vian, X. Fernandez, F. Visinoni, and F. Chemat, "Microwave hydro-diffusion and Gravity, A New Technique for Extraction of Essential Oils," J. Chromatography, vol 1190, pp. 14-17, 2008.

[4]. S. Burt, "Essential Oil: Their antibacterial Properties and Potential Application in Food - A Review," J. Food. Microbiology, vol 94, pp. 223-253, 2004.

[5]. M. Sandasi, G.P.P. Kamato, M. Branska, and A.M. Viljoen, "Application of Vibrational Spectroscopy in the Quality Assessment of Buchu Oil Obtained from Two Commercial Important Agathosma species (Rutaceae)," South Africa J. Botany, vol 76, pp. 692700, 2010.

[6]. E. Chisowa, "Chemical Composition of Essential Oils of Three Eucalyptus Species in Zambia,” J. Essential Oils Res, vol 9, pp. 653-655, 1997.

[7]. M. Gilles, J. Zhao, and S. Agboola, "Chemical Composition and Microbial Properties of Essential Oils of Three Australian Eucalyptus Species," Food Chemistry, vol 199, pp. 731-737, 2010.

[8]. A.E. Petrakis, C.A. Kimbaris, and G.M. Polissious, "Quantitative Determination of Pulegone in Pennyroyal oil by FT-IR Spectroscopy," J. Agriculture and Food Chem, vol 57, pp. 10044-10048, 2009.

[9]. A.M. Cremasco, and P.B. Nazarene, "Thermo gravimetric analysis of Long Pepper (Piper hispidinervium C. DC.) Essential Oil," Acta Amazonica, vol 15, pp. 5967, 2011.

[10]. A. Hazra, K. Alexander, D. Dollimore, and A. Riga, "Characterization of Some Essential Oils and Their Key Components: Thermo analytical techniques," J. Thermal Analysis and Calometry, vol 75, pp. 317-330, 2004.

[11]. M.P. Dewick, Essentials of Organic Chemistry, $1^{\text {st }}$ ed., John Wiley \& Sons: Chichester, 2006, pp.234.

[12]. S. Caron, Practical Synthetic Organic Chemistry: Reactions, Principles and Techniques, $1^{\text {st }}$ ed., Wiley: Hoboken, 2011, pp.75.

[13]. T.W. Solomons, and B.C. Fryhle, Organic Chemistry, $10^{\text {th }}$ ed., John Wiley \& Sons: Asia, 2011, pp.187-890.

[14]. L.G. Wade, Organic Chemistry: Pearson International Edition, $7^{\text {th }}$ ed., Prentice Hall: London, 2010, pp. 379 